\title{
Health Care Commissioning: The UK Health Policy Reforms
}

\author{
Shuby Puthussery*, Krishna Regmi and Gurch Randhawa
}

Department of Clinical Education and Leadership \& Institute for Health Research, University of Bedfordshire, UK

Technology has improved and advancements in healthcare are evident as outcomes people now live longer and can be treated faster, meaning 'adding years to life and life to years' [1,2]. Substantive evidence, however, reveals that health and resources are unequally distributed across the world as a result people still have difficulty in accessing and utilising essential healthcare [3-5]. Reorganisation of public health systems is inevitable now, more than before, to make services more directly accountable to patients and communities, and developed countries are also embarking on healthcare reforms with key policy changes aiming to deliver cost-effective, population-based and patient-oriented outcomes. One of the prominent drivers of these reforms is the continued growth in the cost of healthcare against the wider economic and financial backdrop, where there is an increasing demand for services within tight financial constraints. A classic example is the UK National Health Service (NHS) which is currently undergoing radical changes as outlined by its controversial and much debated Health and Social Care Act 2012, with the notion that this would bring high quality and cost-effective care to local communities [6].

In 2013/14, the first year of the UK's reformed health service, area health authorities known as Primary Care Trusts (PCTs) and Strategic Health Authorities (SHAs) who were largely responsible for the determination of local health challenges and priorities and for the design and delivery of strategies to tackle these challenges, will be abolished from April 2013, and service improvements will be driven by a clinically-led local commissioning system. In this new system, groups of geographically aligned primary care practitioners will come together to create new statutory organisations known as Clinical Commissioning Groups (CCGs) who will take on the responsibility for the direct commissioning of the majority of NHS services with oversight from an umbrella body at the national level, the NHS Commissioning Board (NHSCB) responsible for the effective and economical running of the NHS [7]. The public health function will be transferred from the PCTs to the local governments under the auspicious of Health and Wellbeing Boards (HWBs). The new structure builds on the centrality of practicebased commissioning, taking it a great deal further in primary care with a greater local control of decision-making to improve patient care and outcomes. One school of thought was that the new structure in place would bring 'patient empowerment, local professional judgement and greater provider dynamisms' [6].

While this is a major change to both the philosophy and structures of the past, it will at least take a while to see if the endeavour will stand the test of time. The success or failure of such reforms, however, rests to a great extent on the ability and commitment of primary care practitioners to rise up to the challenge to act as local leaders of the health system and to lead and steer the local health agenda in their community, working collaboratively with clinical, public health and community partners. The other set of challenges will be to ensure that CCGs are able to effectively commission health services from any qualified providers using open and transparent processes. This clearly requires a strong understanding of the health needs of the local population and also that CCGs are able to access public health advice and expertise to inform the way they structure and deliver their services.

The role of public health in commissioning is both strategic and operational. Therefore, it is equally important to adopt a public health system framework that affords maximum flexibility and an inclusive approach, as well as opens an opportunity for representation and engagement of participation in healthcare planning and decisionmaking at the local level [8]. In the new structure, it is imperative that CCGs are full and active members of their local HWBs. The HWBs can make a significant positive contribution towards tackling the wider determinants of health by joining forces with all the local government services. Such a 'whole system' approach will have greater potential towards tackling the socio-economic, environmental and lifestyle drivers of poor health outcomes and in reducing health inequalities.

The obvious benefit, of enabling the local health system to be led by local clinicians is that the commissioning of health services will focus much more on the importance of patient care outcomes and the quality of services being delivered by local provider services, including those services provided within primary care by local GPs [9]. The international evidence on successful commissioning suggests that the impact of commissioning will to some extent depend on the degree to which politicians are willing to 'let go' and allow commissioners to exercise their leverage, even if the consequences are unpopular with the public to commission services that optimise health gains and reduce health inequalities [10]. Such an approach will go a long way in empowering local clinicians to deliver better outcomes with increased information for patients to make choices and greater accountability to the communities the NHS serves as envisioned by the NHS Commissioning Board [11].

\section{References}

1. Department of Health (2008) Word class commissioning

2. Rowe R (2009) A guide to commissioning in the NHS and its effects on clinical care. Nurs Stand 23: 51-56.

3. Marmot M (2010) Fair society, healthy lives: The Marmot review; strategic review of health inequalities in England post-2010. Marmot Review, London.

4. Hunter DJ, Marks L, Smith KE (2010) The public health systems in England. The Policy Press, Bristol.

5. World Bank (2004) Marking services work for poor people. World Bank, Washington DC.

6. Steven S (2010) More brickbats then bouquets. BMJ 341: c3977.

7. Department of Health (2012) Health and social care act explained.

8. Maxwell RJ (1992) Dimensions of quality revisited: from thought to action. Qual Health Care 1: 171-177.

9. North West Strategic Health Authority (2011) The new NHS commissioning architecture.

*Corresponding author: Shuby Puthussery, Department of Clinical Education and Leadership, Institute for Health Research, University of Bedfordshire, Luton LU2 8LE, UK, Tel: 44(0)1582-743-313; E-mail: shuby.puthussery@beds.ac.uk

Received January 15, 2013; Accepted January 17, 2013; Published January 19 2013

Citation: Puthussery S, Regmi K, Randhawa G (2013) Health Care Commissioning: The UK Health Policy Reforms. Primary Health Care S5: e001. doi:10.4172/2167 1079.S5-001

Copyright: (c) 2013 Puthussery S, et al. This is an open-access article distributed under the terms of the Creative Commons Attribution License, which permits unrestricted use, distribution, and reproduction in any medium, provided the original author and source are credited. 
Citation: Puthussery S, Regmi K (2013) Health Care Commissioning: The UK Health Policy Reforms. Primary Health Care S5: e001. doi:10.4172/21671079.S5-001

10. Ham C (2008) World class commissioning: a health policy chimera? J Health Serv Res Policy 13: 116-121.
11. NHS Commissioning Board (2012) Everyone counts: planning for patients 2013/14. 